\title{
QUALIDADE DAS ÁGUAS RESIDUÁRIAS DO PROCESSO DE ARMAZENAGEM PRÉVIA, POR IMERSÃO, DE FRUTOS DO CAFEEIRO
}

\author{
Marise Cota Machado ${ }^{1}$, Juarez de Sousa e Silva ${ }^{2}$, Antonio Teixeira de Matos 3 , \\ Paola Alfonsa Vieira Lo Monaco ${ }^{4}$
}

\begin{abstract}
RESUMO
O armazenamento prévio consiste na manutenção dos frutos do cafeeiro recém-colhidos imersos em água, possibilitando o ajuste entre o volume de frutos colhidos e a capacidade de processamento disponível, sem prejuízo à qualidade final dos grãos. Neste trabalho, objetivou-se avaliar algumas características químicas e bioquímicas das águas residuárias geradas no processo, visando avaliar a necessidade de seu tratamento para lançamento em corpos hídricos ou as possibilidades de aproveitamento como fertilizante agrícola.Na geração da água residuária, foram utilizados lotes de frutos de diferentes características e origens, sendo que os períodos de armazenagem avaliados variaram de 1 a 5 dias. As variáveis quantificadas nas águas residuárias foram $\mathrm{DBO}, \mathrm{DQO}$ e as concentrações de $\mathrm{P}, \mathrm{N}, \mathrm{K}$ e Na. Com base nos resultados obtidos e nas condições estabelecidas para o experimento, pôde-se concluir que a concentração dos nutrientes na água residuária de imersão varia com o estágio de maturação dos frutos e, no geral, com o grau de deterioração do produto, indicando uso potencial para fertirrigação de culturas agrícolas.
\end{abstract}

Palavras-chave: café, processamento, águas residuárias, imersão, fertirrigação.

\section{ABSTRACT \\ QUALITY OF WASTEWATER FROM PRE-DRYING COFFEE CHERRY STORAGE BY IMMERSION METHOD}

To maintain the final grain quality, the harvested coffee cherry are stored immersed in water, to adjust harvested volume and the processing capacity. This study reports some chemical and biochemical characteristics of the water left after storage, to assist decision making for its treatment for river discharge or for agricultural use such as fertilizing. Coffee cherries of different characteristics and origins were used, and BOD, COD and concentration of $\mathrm{P}, \mathrm{N}, \mathrm{K}$ and $\mathrm{Na}$ was determined after the storage period of 1 to 5 days. The data showed that the concentration of the nutrients in the immersion water is related to fruit maturation and, in general, also to the degree of cherry deterioration, and this water has potential for fertirrigation.

Keywords: coffee, processing, wastewaters, immersion, fertirrigation.

\footnotetext{
Recebido para publicação em 13/09/2011. Aprovado em 11/09/2012.

1- Engenheira Agrícola, D.S em Engenharia Agrícola, UFV, Viçosa-MG, juarez@ufv.br.

2- Eng. Agrônomo, Ph.D, Professor Voluntário do Depto. de Engenharia Agrícola, UFV, Viçosa-MG.

3- Engenheiro Agrícola, Prof. Associado, Depto. de Engenharia Agrícola, UFV, Viçosa-MG.

4- Engenheira Agrícola, Profa. do IFES, campus Centro Serrano, Santa Maria de Jetibá-ES.
} 


\section{INTRODUÇÃO}

A modernização da cafeicultura, evidenciada pela adoção de tecnologias no processamento dos frutos do cafeeiro, promoveu um avanço qualitativo e econômico nas atividades de preparo dos grãos de café, com menores custos de produção, além de melhores perspectivas de obtenção de um produto de boa qualidade. No processamento diário, muitas vezes ocorrem problemas por inadequação da capacidade do maquinário ao volume de frutos colhidos. Assim, é comum ocorrer o amontoamento de frutos ensacados ou a granel, em pátios, à espera do processamento, período em que pode ocorrer sério comprometimento à qualidade da bebida, tendo em vista que há a exposição dos frutos às intempéries, à fermentação e ao desenvolvimento de microrganismos.

A armazenagem prévia dos frutos do cafeeiro é uma técnica proposta por Machado (2005) e que tem como objetivo otimizar o processamento dos frutos do cafeeiro, possibilitando o ajuste entre o volume de frutos colhidos e a capacidade da unidade de processamento. A técnica consiste na manutenção dos frutos recém-colhidos imersos em água, de modo a adequar os lotes ao processo de secagem, sem prejuízo à qualidade final dos grãos.

A imersão de frutos do cafeeiro como alternativa no gerenciamento das atividades de colheita $\mathrm{e}$ processamento é uma técnica inovadora, não havendo, portanto, referências bibliográficas que caracterizem o processo, assim como a disposição do resíduo gerado.

O tratamento e, ou, a disposição final das águas residuárias do processo de armazenagem prévia dos frutos (imersão) ou mesmo nas atividades de separação hidráulica e descascamento dos frutos, são aspectos importantes na produção sustentada, sem agressão ao meio ambiente. De acordo com Matos (2008), as atividades de separação hidráulica e descascamento de frutos são geradoras de grandes volumes de resíduos sólidos e líquidos, ricos em material orgânico e inorgânico que, se dispostos no meio ambiente sem tratamento, podem causar grandes problemas ambientais como degradação ou destruição da flora e da fauna, além de comprometer a qualidade da água e do solo.

Dentre as soluções propostas para tratamento de águas residuárias ricas em material orgânico, destaca-se a sua disposição sobre o solo. Matos e Lo Monaco (2003) citam como vantagens da disposição de águas residuárias sobre o solo, o benefício agrícola, o baixo investimento relativo (custo oscila entre 30 e $50 \%$ do custo do tratamento convencional), o pequeno custo de operação e o reduzido consumo de energia.

No que se refere ao valor como fertilizante de culturas agrícolas, a água residuária do processamento de frutos do cafeeiro apresenta concentrações relativamente elevadas de nitrogênio, fósforo, cálcio e, principalmente, de potássio, indicando que essa água possui elevado valor fertilizante e que pode ser aproveitada e disposta no solo, com o objetivo de substituir alguns fertilizantes inorgânicos utilizados no cultivo agrícola (LO MONACO et al., 2007; LO MONACO et al., 2009a). Além disso, Carvalho et al. (2008) ressaltam que a utilização de águas residuárias em lavouras ou para tratamento resulta em importantes contribuições para a melhoria dos recursos hídricos da região, como a redução do volume de água captada em rios ou lagos para fins de irrigação e a minimização da poluição pela redução do lançamento de águas residuárias nos mananciais hídricos.

Pouco se sabe sobre as características da água residuária gerada no processo de imersão dos frutos do cafeeiro. Dessa forma, a análise da qualidade desse efluente, sob o ponto de vista do impacto ambiental, resulta na avaliação da sua tratabilidade, bem como no estudo da potencialidade de seu aproveitamento agrícola como fertilizante, que são aspectos importantes a serem considerados para dar viabilidade ao processo. O conhecimento das características físicas, químicas e bioquímicas do efluente é fundamental no dimensionamento de sistemas de tratamento e, ou, disposição final das águas residuárias do processo de imersão dos frutos do cafeeiro.

Neste trabalho, objetivou-se avaliar as características químicas e bioquímicas das águas residuárias geradas no processo de armazenagem temporária de frutos do cafeeiroimersos em água, visando seu tratamento para lançamento em corpos hídricos ou aproveitamento agrícola, quando aplicado em fertirrigação.

\section{REVENG} 443-452 $\mathrm{p}$. 


\section{MATERIAIS E MÉTODOS}

O experimento foi conduzido na Área de Pré-processamento de Produtos Agrícolas do Departamento de Engenharia Agrícola da Universidade Federal de Viçosa, em Viçosa, MG.

Do estudo de qualidade do grão de café, cujos frutos foram armazenados por imersão em água e, posteriormente, processados, foram aproveitadas as soluções usadas na conservação dos frutos que, ao serem descartadas após o período de armazenamento, passaram a constituir os efluentes ou águas residuárias, objeto de caracterização neste trabalho. Para o estudo de armazenagem prévia por imersão, foram utilizados lotes de frutos do cafeeiro de diferentes características e origens, assim discriminadas:

Café A: amostra contendo frutos maduros, colhidos seletivamente, com ausência de frutos verdes, proveniente de Teixeiras, MG;

Café B: amostra contendo frutos maduros, colhidos seletivamente, proveniente de Paula Cândido, MG;

Café $\mathrm{C}$ : amostra contendo pequena porcentagem de frutos verdes pesados (abaixo de $5-10 \%$ de verdes), proveniente de Araponga, MG.

Café D: amostra contendo elevado conteúdo (25-30\%) de frutos verdes pesados e, visualmente, com incidência menor que $1 \%$ de frutos brocados, proveniente de Viçosa, MG.

Os frutos recém-colhidos eram recebidos à tarde, sendo encaminhados para a separação hidráulica, para a obtenção das frações cereja e bóia. $\mathrm{O}$ lavador utilizado foi um lavador mecânico (menor modelo da Pinhalense), com injeção contínua de, aproximadamente, trinta litros de água (proveniente do serviço de abastecimento da UFV) por minuto. Foram realizados testes de imersão em água tratada, sendo que as distintas frações de frutos cereja e frutos bóia foram armazenados em tanques individualizados, por diferentes períodos de imersão em água. A proporção de água e frutos (cerejas ou bóias) foi padronizada em 1:1 em volume. A cada 24 horas, a água de armazenagem temporária era substituída por um novo volume. Antes de realizar o descarte diário da água de armazenagem, parte dela era reservada como amostra para as análises físicas, químicas e bioquímicas.

Devido aos procedimentos de coleta de amostras e de troca de água adotados, os resultados foram expressos em relação ao estágio da imersão, ou seja, referentes ao número de trocas de água (após 24 horas de imersão: água da $1^{\text {a. }}$ troca; após 48 horas, água da $2^{\text {a. }}$ troca e, assim, sucessivamente). Devido à indisponibilidade de secadores e à sequência de colheita, não foi possível aplicar o mesmo tratamento para os frutos originados das diferentes localidades, daí a presença de falhas nas tabelas de resultados.

Os períodos de armazenagem avaliados variaram de 1 a 5 dias e as variáveis quantificadas nas águas residuárias do processo, coletadas nos tanques de imersão, foram Demanda Bioquímica de Oxigênio (DBO), quantificando-se o oxigênio dissolvido pelo método iodométrico (Processo Winkler); Demanda Química de Oxigênio (DQO), pelo método de oxidação química em refluxo aberto; as concentrações de fósforo, por espectrofotometria; potássio e sódio, por fotometria de chama e nitrogênio, pelo processo semimicro Kjeldahl (APHA et al., 2005).

\section{RESULTADOS E DISCUSSÃO}

Na Figura 1 estão apresentadas as variações na coloração da água residuária, em consequência da troca diária.

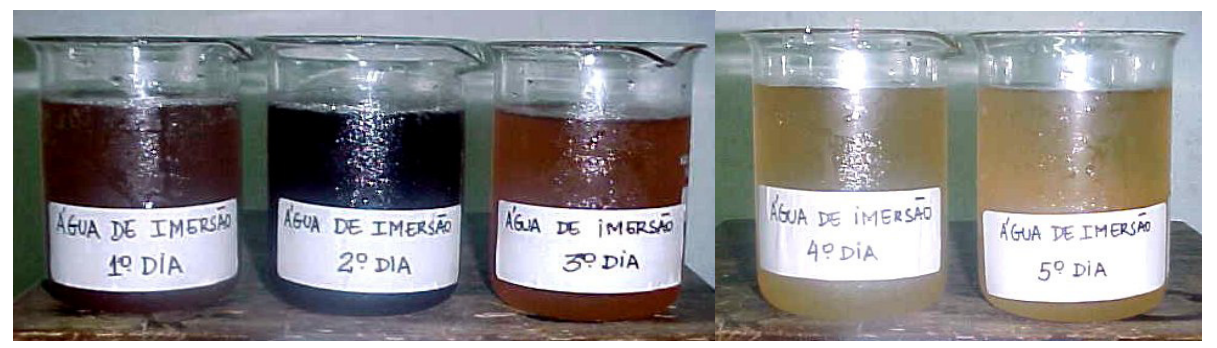

Figura 1. Coloração das águas residuárias (troca diária) provenientes da imersão de café cereja em água proveniente do sistema de tratamento da UFV. 
Observa-se que a água residuária dos primeiros dias de imersões apresentava coloração vermelha que perde a intensidade a cada troca diária. Isso é decorrente da solubilização de compostos químicos responsáveis pela coloração avermelhada da casca.

Os resultados das análises de DBO e DQO das águas residuárias do armazenamento dos frutos do cafeeiro, por imersão, em diferentes estágios, estão apresentados nos Quadros 1 e 2.

No Quadro 1 estão apresentados resultados das análises de Demanda Bioquímica de Oxigênio na água de imersão dos diferentes lotes.

Os resultados apresentados no Quadro 1 indicaram haver importante influência do estágio da imersão bem como de diferenças nas características dos frutos de cada lote no valor da DBO.

Em todos os lotes, a DBO foi decrescente a cada estágio da imersão dos frutos. Foi possível observar que os menores valores obtidos ocorreram na água que esteve em contato com lotes que continham maior proporção de frutos verdes, seguidos pelos lotes de frutos bóia e pelos de frutos cereja. O menor valor de DBO, proporcionada com a imersão dos lotes com frutos verdes, indica que a concentração de compostos hidrossolúveis que são translocados dos frutos para a solução varia com o grau de maturação dos frutos. Os frutos tipo bóia, devido às perdas advindas da secagem dos frutos no campo, proporcionaram a obtenção de uma água residuária que apresentou menores valores de DBO que a obtida na imersão dos frutos cereja, porém, superiores àqueles obtidos na imersão dos lotes cereja + verdes pesados.

Os lotes A1 a A5, constituídos por frutos cereja, colhidos na mesma lavoura, embora em dias diferentes, apresentaram diferenças tanto na maturação (coloração dos frutos) como nos procedimentos anteriores à imersão (o lote $\mathrm{A} 5$ permaneceu ensacado por 24 horas) e, com isso, proporcionaram valores diferentes, mas sempre elevados de DBO na água residuária de primeiro estágio. Os frutos dos lotes

Quadro 1. Valores de Demanda Bioquímica de Oxigênio (DBO), em $\mathrm{mg} \mathrm{L}^{-1}$, na água de imersão de frutos de cafeeiro tipo cereja e tipo bóia oriundos das diferentes localidade (' $\mathrm{A}=$ Teixeiras', 'B = Paula Cândido', 'C = Araponga' e 'D = Viçosa')

\begin{tabular}{cccccc}
\hline & \multicolumn{5}{c}{ Período de Imersão / troca } \\
\cline { 2 - 6 } Água & $\begin{array}{c}\mathbf{2 4} \mathbf{h} \\
\mathbf{1}^{\text {a. }} \text { troca }\end{array}$ & $\begin{array}{c}\mathbf{4 8} \mathbf{~} \\
\mathbf{2}^{\text {a. }} \text { troca }\end{array}$ & $\begin{array}{c}\mathbf{7 2} \mathbf{~ h} \\
\mathbf{3}^{\text {a. }} \text { troca }\end{array}$ & $\begin{array}{c}\mathbf{9 6} \mathbf{~ h} \\
\mathbf{4}^{\text {a. }} \text { troca }\end{array}$ & $\begin{array}{c}\mathbf{1 2 0} \mathbf{~ h} \\
\mathbf{5}^{\text {a. }} \text { troca }\end{array}$ \\
\hline D2 & 3.577 & - & - & - & - \\
D1 & 3.677 & 2.140 & 1.311 & - & - \\
B2 & 4.382 & 2.607 & 1.535 & - & - \\
B2 bóia & 4.907 & 1.510 & 1.006 & - & - \\
B1 bóia & 5.296 & 2.350 & 1.854 & 1.237 & - \\
A3 & 5.910 & 1.461 & 732 & & \\
B1 & 6.632 & 4.789 & 2.132 & 1.025 & 501 \\
A1 & 6.679 & 2.871 & 1.222 & 122 & 240 \\
A2 & 6.879 & 3.490 & 498 & 213 & - \\
D1 bóia & 9.363 & 9.105 & 2.213 & - & - \\
A4 & 10.161 & 2.494 & 866 & - & - \\
B3 & 12.715 & 3.311 & - & - & - \\
C1 & 16.972 & 13.600 & 4.232 & - & - \\
A5 & 23.291 & 2.563 & 803 & - & - \\
\hline
\end{tabular}

Café: A(1,2, 3, 4 e 5): lotes de frutos de café cereja, colhidos de forma seletiva, praticamente com ausência de frutos verdes, provenientes de Teixeiras, MG. Lote A4: permaneceu ensacado por 12 horas antes da imersão (armazenagem em água); A5: permaneceu ensacado por 24 horas antes da imersão (armazenagem em água).

Café: B(1,2 e 3), lotes de frutos cereja e B(1 e 2) bóia,lotes de frutos bóias, provenientes de Paula Cândido, MG.

Café $\mathrm{C} 1$ : lote de frutos (cereja + verdes pesados), contendo de 5 a $10 \%$ de verdes, provenientes de Araponga, MG.

Cafés $\mathrm{D}(1$ e 2): lotes de frutos (cereja + verdes pesados), com 25-30\% de verdes e $\mathrm{D}(1)$ bóia, café bóia proveniente de Viçosa, MG. 
A4 e A5, por terem ficado ensacados por 12 e 24 horas, respectivamente, após a colheita, devido a problemas operacionais, apresentaram indícios de deterioração, tais como elevada temperatura da massa de grãos e odor característico da fermentação, o que proporcionou a obtenção dos maiores valores de DBO na água residuária de primeiro estágio, dentre os lotes de Café A. Os lotes B1 e B2, constituídos por frutos cereja, colhidos seletivamente (percentual maior que $98 \%$ de frutos cereja), proporcionaram valores medianos de concentração de DBO na água residuária do primeiro estágio. O lote $\mathrm{B} 3$, por ser constituído por frutos cereja (percentual maior que $98 \%$ de frutos cereja), em estágio avançado de maturação, quando comparado com B1 e B2, também proporcionou valores altos de $\mathrm{DBO}$ na água residuária gerada no primeiro estágio. Já os lotes D1 e D2, por serem constituídos por frutos cereja, visualmente, com elevado percentual de brocados $(20 \%)$ e de frutos verdes pesados $(30 \%)$, foram os que proporcionaram menores valores iniciais de DBO na água residuária do primeiro estágio. Os maiores valores encontrados para a DBO na água de imersão de bóias (Café D) pode estar associados à incidência de broca nos frutos maduros, tendo em vista que foi possível perceber, depois de efetuada a operação de lavagem desse lote, grande presença de frutos maduros (maior que $80 \%$ ) na fração bóia. Frutos maduros, notadamente quando na condição bóia, que possibilita maior contato com a água de imersão com o produto, proporcionam a solubilização de grande quantidade de material orgânico, que permanece solúvel na água.

Segundo Matos (2008), a DBO de águas residuárias do descascamento e desmucilagem dos frutos, sem recirculação, está em torno de $2.525 \mathrm{mg} \mathrm{L}^{-1}$ e de 10.500 a $14.340 \mathrm{mg} \mathrm{L}^{-1}$ com recirculação. Os valores obtidos na água de imersão foram mais elevados que os valores de DBO de águas residuárias do descascamento e desmucilagem dos frutos, sem recirculação, devido ao longo período de imersão e à relação entre os volumes de água e de frutos, bem menor que a utilizada nos lavadores e descascadores. Em alguns casos, como nos lotes A4 e A5, os valores de DBO foram semelhantes aos obtidos em águas residuárias com recirculação no processamento dos frutos do cafeeiro.

No Quadro 2 estão apresentados resultados das análises de Demanda Química de Oxigênio na água de imersão dos diferentes lotes.

Quadro 2. Valores de Demanda Química de Oxigênio (DQO), em $\mathrm{mg} \mathrm{L}^{-1}$, na água de imersão de frutos de cafeeiro tipo cereja e tipo bóia (Lotes 'A', 'B', 'C' e 'D')

\begin{tabular}{|c|c|c|c|c|c|}
\hline \multirow[b]{2}{*}{ Lotes } & \multicolumn{5}{|c|}{ Período de Imersão/troca } \\
\hline & $\begin{array}{c}24 \mathrm{~h} \\
\text { 1. }^{\text {a. }} \text { troca }\end{array}$ & $\begin{array}{c}48 \mathrm{~h} \\
\text { 2 }^{\text {a. }} \text { troca } \\
\end{array}$ & $\begin{array}{c}72 \mathrm{~h} \\
\text { 3 }^{\text {a. }} \text { troca } \\
\end{array}$ & $\begin{array}{c}96 \mathrm{~h} \\
4^{\text {a. }} \text { troca }\end{array}$ & $\begin{array}{c}120 \mathrm{~h} \\
5^{\text {a. }} \text { troca }\end{array}$ \\
\hline D2 & 7.285 & & & & \\
\hline D1 & 7.846 & 4.110 & 2.802 & & \\
\hline B2 bóia & 9.333 & 6.667 & 3.333 & & \\
\hline B1 bóia & 20.000 & 16.000 & 8.000 & 2.667 & \\
\hline D bóia & 20.174 & 13.823 & 5.417 & & \\
\hline B2 & 25.333 & 14.667 & 8.000 & & \\
\hline B1 & 25.333 & 25.333 & 14.667 & 10.000 & 8.000 \\
\hline A2 & 26.712 & 19.054 & 4.670 & 3.175 & \\
\hline A3 & 27.460 & 6.538 & 6.538 & & \\
\hline A4 & 27.460 & 12.329 & 14.010 & & \\
\hline $\mathrm{A} 1$ & 30.822 & 13.076 & 7.098 & 2.802 & 1.868 \\
\hline B3 & 55.333 & 18.667 & & & \\
\hline $\mathrm{C} 1$ & 59.176 & 47.796 & 15.932 & & \\
\hline A5 & 164.384 & 25.218 & 3.736 & & \\
\hline
\end{tabular}

Café: A(1,2,3,4 e 5): lotes de frutos de café cereja, colhidos de forma seletiva, praticamente com ausência de frutos verdes, provenientes de Teixeiras, MG. Lote A4: permaneceu ensacado por 12 horas antes da imersão (armazenagem em água); A5: permaneceu ensacado por 24 horas antes da imersão (armazenagem em água);

Café: $\mathrm{B}(1,2$ e 3), lotes de frutos cereja e B(1e2) bóia, lotes de frutos bóias, provenientes de Paula Cândido, MG.

Café $\mathrm{C} 1$ : lote frutos (cereja + verdes pesados) (5-10\% de verdes), provenientes de Araponga, $\mathrm{MG}$,

Café $\mathrm{D}(1$ e 2): lotes de frutos (cereja + verdes pesados), com 25-30\% de verdes e $\mathrm{D}(1)$ bóia, café bóia provenientes de Viçosa, MG. 
Observa-se o mesmo comportamento verificado para a DBO, ou seja, a água de imersão de amostras de maior percentual de frutos verdes apresentou os menores valores de DQO, seguidas pelas da imersão de amostras de frutos bóia e frutos cereja. O valor de DQO mais elevado na água de imersão dos frutos bóia do café ' $\mathrm{D}$ ' pode estar associado à alta incidência de frutos maduros na fração bóia (visualmente, pela incidência de broca).

Os valores observados são, de modo geral, maiores que os valores de DQO em água residuária da lavagem e descascamento/despolpa de frutos cereja, sem recirculação, e que estão em torno de $5.148 \mathrm{mg} \mathrm{L}^{-1}$, enquanto algumas amostras da água residuária coletadas, notadamente as obtidas após $24 \mathrm{~h}$ de imersão ( $1^{\mathrm{a}}$ troca), apresentaram-se com DQO no intervalo de 18.000 a $29.500 \mathrm{mg} \mathrm{L}^{-1}$, citado por Matos (2008) como sendo o normal para água residuária resultante da descascamento/ despolpa em equipamentos com recirculação.

As concentrações individuais de DQO e DBO, bem como a relação entre elas, são variáveis a serem utilizadas na escolha do tratamento adequado das águas residuárias. Avaliando-se os dados obtidos para a DQO e a DBO no processo de imersão, observa-se que a diminuição na DQO da água residuária com o aumento do número de trocas de água (número de estágio) ocorreu em menor intensidade quando comparada à DBO; ou seja, a fração orgânica apresentou maior solubilidade em água do que a fração composta por substâncias inorgânicas ou orgânicas de difícil decomposição.

A DQO da água de imersão dos frutos cereja, coletada antes das $2^{\mathrm{a}}$ e $3^{\mathrm{a}}$ trocas, foi reduzida, em média, de 45 a $70 \%$, respectivamente, em relação à DQO da água de imersão coletada na $1^{\text {a. }}$ troca. A DBO, por sua vez, foi reduzida em média, de 60 a $80 \%$ em relação à DBO da água de imersão coletada na $1^{\text {a. }}$ troca. Em relação aos frutos tipo bóia, a DQO da água de imersão coletada nas $2^{\text {a. }}$ e $3^{\text {a. }}$ trocas, foi reduzida, em média, de 32,5 a $69 \%$, respectivamente, em relação à $\mathrm{DQO}$ da água de imersão coletada na $1^{\text {a. }}$ troca. A DBO, por sua vez, foi reduzida em média, de 48 a $70 \%$ em relação à $\mathrm{DBO}$ da água de imersão coletada na $1^{\text {a. }}$ troca.

Na Figura 2 está ilustrada a variação da relação DQO/DBO em relação ao estágio de imersão. A não ser no caso do Café $\mathrm{D}$, constituído por bóia, houve tendência de aumento na relação $\mathrm{DQO} / \mathrm{DBO}$ com o número de trocas da água, evidenciando maior dificuldade do tratamento biológico da água residuária com o tempo de armazenagem dos frutos. Os resultados da relação DQO/DBO obtidos nesse trabalho foram superiores aos obtidos por Matos (2008) e por Rigueira et al. (2010), que obtiveram 2,0 e 2,9, respectivamente, utilizando águas residuárias do descascamento/desmucilagem de frutos do cafeeiro, sendo um indicativo de maiores dificuldades no tratamento apenas biológico das águas de imersão, quando comparadas à água residuária do descascamento/despolpa.

Nos Quadros 3 e 4 estão apresentados, respectivamente,os resultados de concentração de $\mathrm{N}, \mathrm{P}, \mathrm{K}$ e Na nas águas de imersão do lote de frutos cereja e do lote de frutos bóia.

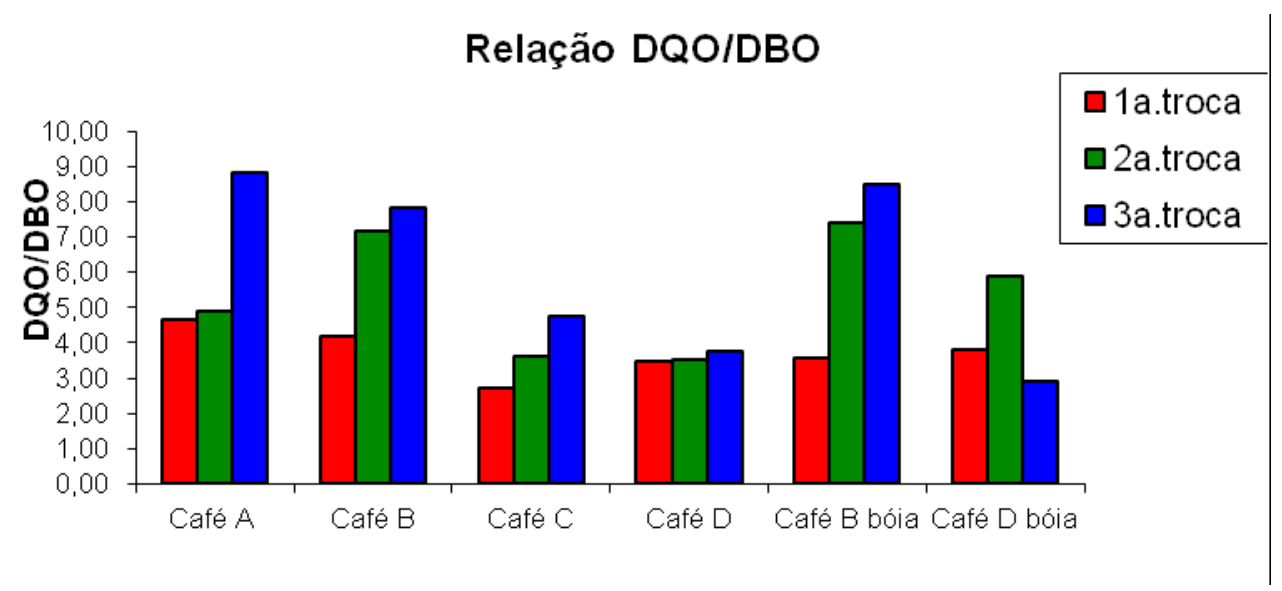

Figura 2. Representação gráfica da variação da relação DQO/DBO em função do estágio de imersão dos diferentes lotes estudados.

448 REVENG

443-452 p. ENGenharia NA AGRICULTURA, VIÇOSA - MG, V.20 N.5, SETEMBRO / OUTUBRO 2012 


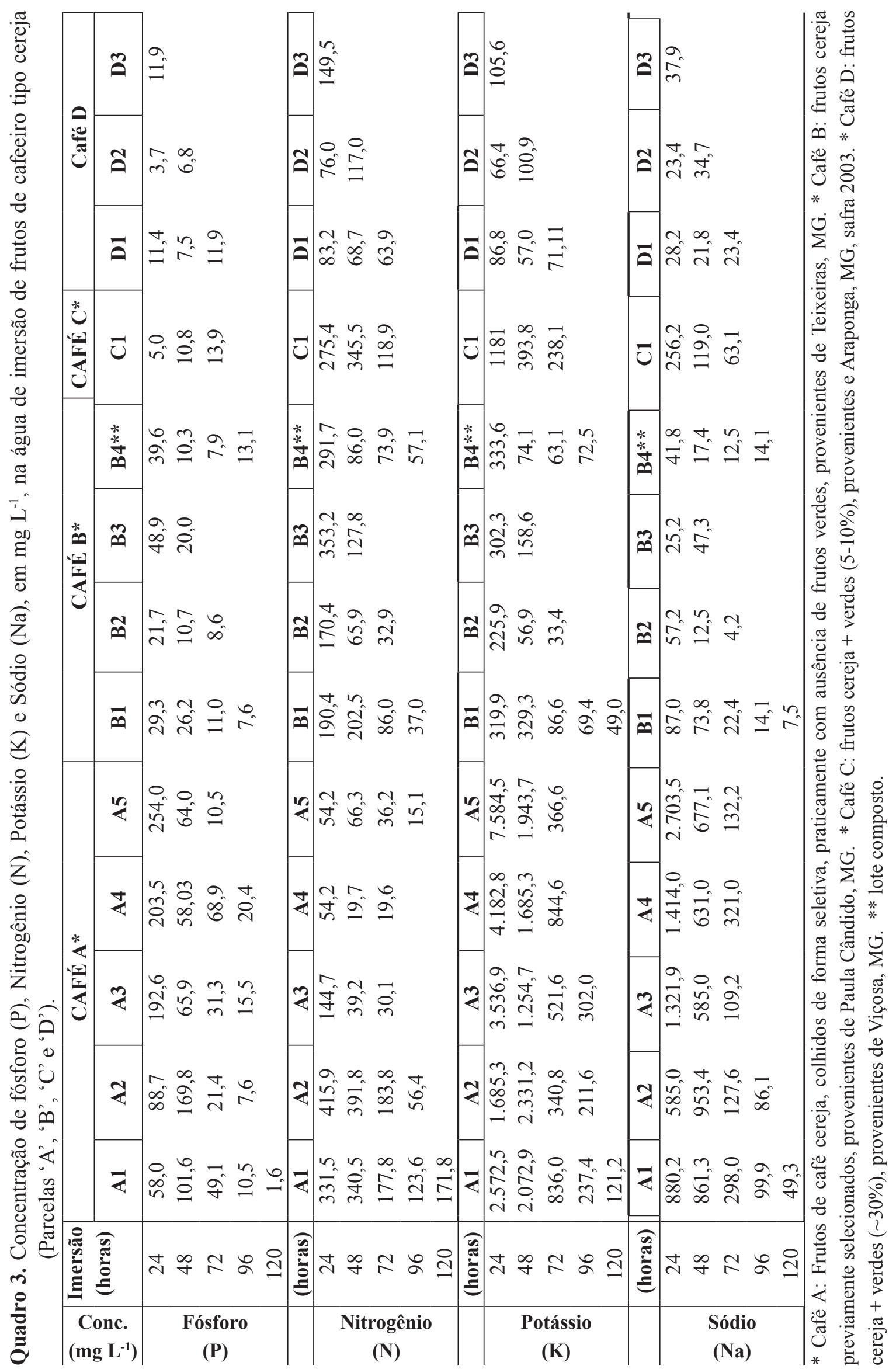


Quadro 4. Concentração de fósforo (P), Nitrogênio (N), Potássio (K) e Sódio (Na), em mg L L ${ }^{-1}$ da água de imersão de frutos de cafeeiro tipo bóia (Parcelas 'B' e 'D')

\begin{tabular}{cc|c|c|c}
\hline \multirow{2}{*}{$\begin{array}{c}\text { Conc. } \\
\left(\mathbf{m g ~ L} \mathbf{~}^{-1}\right)\end{array}$} & $\begin{array}{c}\text { Imersão } \\
\text { (horas) }\end{array}$ & \multicolumn{3}{|c}{ CAFÉS BÓIAS } \\
\cline { 2 - 5 } & & B1 bóia & B2 bóia & D1 bóia \\
\hline \multirow{2}{*}{ Fósforo } & 24 & 37,2 & 17,6 & 41,61 \\
$(\mathrm{P})$ & 48 & 16,9 & 8,6 & 32,2 \\
& 72 & 7,6 & 4,1 & 14,0 \\
\hline & 96 & 11,0 & & 448,4 \\
Nitrogênio & 24 & 219,4 & 118,1 & 379,7 \\
$(\mathrm{~N})$ & 48 & 119,7 & 54,6 & 124,2 \\
& 72 & 51,4 & 21,7 & 522,9 \\
\hline & 96 & 16,7 & & 522,9 \\
Potássio & 24 & 302,3 & 210,3 & 124,4 \\
$(\mathrm{~K})$ & 48 & 241,6 & 91,3 & 18,6 \\
& 72 & 49,0 & 33,4 & 18,6 \\
\hline & 96 & 27,1 & & 46,0 \\
\hline
\end{tabular}

Café B(1 e 2): lotes de frutos bóia, provenientes de Paula Cândido, MG.

Café D1: lote de frutos bóia,provenientes de Viçosa, MG.

Verificou-se haver correlação entre a concentração de fósforo, potássio e nitrogênio e características de maturação e conservação dos frutos, tendo sido observado no Lote A os maiores valores. Pode-se observar também, que nas primeiras 24 e 48 horas de imersão ( $1^{\mathrm{a}}$ e $2^{\mathrm{a}}$ trocas), houve maior solubilização de nutrientes e sódio contidos nos frutos para a água, proporcionando elevação da concentração na mesma.

Dos lotes que apresentaram indícios de fermentação (A4 e A5), as amostras apresentaram elevadas concentrações de $\mathrm{P}$ e $\mathrm{K}$ e menores de N. Estes fatos levam a crer que o processo de deterioração favoreceu a disponibilização de $\mathrm{P}$ e $\mathrm{K}$ na água de imersão. As menores concentrações de $\mathrm{N}$ na água podem estar associadas à menor solubilidade desse nutriente ou à possível ocorrência de perdas de amônia, por volatilização.

Os resultados das análises também mostraram diferenças nas concentrações das diferentes espécies químicas em relação à procedência dos frutos, indicando alta variabilidade nas características físicas e químicas nas águas residuárias geradas na imersão de frutos provenientes de diferentes lavouras. Os frutos provenientes de Teixeiras, MG (Café 'A'), por exemplo, proporcionaram a produção de uma água de residuária do processo de imersão com maiores concentrações de $\mathrm{P}, \mathrm{K}$ e $\mathrm{Na}$ que os frutos provenientes de Paula Cândido, MG (Café 'B'). Estas diferenças podem estar, também, associadas à incidência de broca, presente no café 'A' e praticamente ausente no café 'B', que pode ter proporcionado maior superfície de contato da água com o interior do grão, mas também à adubação da lavoura.

Os elevados valores de $\mathrm{P}$ e $\mathrm{K}$, obtidos principalmente nos Lotes A e nas primeiras 24 e 48 horas imersão, confirmam o potencial fertilizante dessa água residuária, podendo ser aplicada na fertirrigação de culturas agrícolas. Nas primeiras 24 horas de imersão dos frutos dos lotes $\mathrm{A}$, foram obtidas concentrações de 58,0 a $254,0 \mathrm{mg} \mathrm{L}^{-1}$ de $\mathrm{P}$ e de $2.572,0$ a $7.584,5 \mathrm{mg} \mathrm{L}^{-1}$ de $\mathrm{K}$, valores substancialmente superiores aos obtidos em 
águas residuárias provenientes do descascamento/ desmucilagem dos frutos do cafeeiro, que, de acordo com Rigueira et al. (2010) estão na faixa de 1,61 a $22,50 \mathrm{mg} \mathrm{L}^{-1}$ de $\mathrm{P}$ e em torno de $157,0 \mathrm{mg} \mathrm{L}^{-1}$ de K, colhido na região de Ervália-MG. Os valores obtidos neste trabalho foram, também, maiores que os citados na literatura para águas residuárias do descascamento/despolpa mais concentradas, isto é, aquelas obtidas quando há a recirculação da água no processo, que, segundo Matos (2008), estão em torno de 16 e $1.140 \mathrm{mg} \mathrm{L}^{-1}$, respectivamente, para $\mathrm{P}$ e K.

Assim como no caso do $\mathrm{P}$ e o $\mathrm{K}$, foram obtidas elevadas concentrações de $\mathrm{Na}$ (na faixa de 585,0 a $2.703,5 \mathrm{mg} \mathrm{L}^{-1}$ ) na água de imersão dos frutos do cafeeiro, notadamente naqueles provenientes de Teixeiras. Esses valores de concentração estão altos mesmo em relação aos obtidos com a imersão de frutos cereja provenientes de outras localidades. Considerando-se que a concentração de $\mathrm{N}, \mathrm{P}$ e $\mathrm{K}$ também foram maiores na água de imersão dos frutos cereja provenientes de Teixeiras, suspeita-se que isso esteja associado à adubação do solo, especulando-se que, nessa lavoura, a disponibilidade de nutrientes tenha sido muito maior para as plantas.

Os tratamentos de águas residuárias não removem sódio e o potássio por processos convencionais, em razão de suas altas solubilidades, eles não ficam retidos em estruturas como sedimentadores ou filtros (LO MONACO et al., 2004; LO MONACO et al., 2009b). Desta forma, o tratamento/disposição da água residuária gerada no processo de imersão via fertirrigação de culturas agrícolas se torna conveniente, porém, torna-se recomendável o monitoramento da concentração de sódio trocável no solo, já que elevadas concentrações em relação aos outros cátions como o cálcio e o magnésio, oferecem risco de dispersão da argila no solo. De acordo com Almeida Neto et al. (2009), as partículas finas de um solo assim dispersado, obstruem o seu espaço poroso, reduzindo acentuadamente a infiltração da água. Além da diminuição da quantidade de água disponível para as culturas, formam-se crostas superficiais que levam a problemas de germinação e emergência de plântulas. Entretanto, segundo os mesmos autores, caso a água residuária apresente elevada condutividade elétrica, esse risco passa a ser mínimo.

\section{CONCLUSÃO}

Com base nos resultados obtidos e nas condições estabelecidas no experimento, pode-se concluir que:

- A DBO e a DQO decresceram na água de imersão, em amostras coletadas por ocasião de cada troca;

- O estágio de maturação, assim como o grau de deterioração dos frutos afetaram os valores de DBO, DQO econcentração dos nutrientes na água de imersão; e

- A água de imersão apresentou altas concentrações de N, P, K, podendo ser utilizada na fertirrigação de culturas agrícolas, entretanto, nesse caso, há de se monitorar as quantidades aplicadas de $\mathrm{Na}$.

\section{REFERÊNCIAS BIBLIOGRÁFICAS}

ALMEIDA NETO, O.B.; MATOS, A.T.; ABRAHÃO, W.A.P.; COSTA, L.M.; DUARTE, A. Influência da qualidade da água de irrigação na dispersão da argila de latossolos. Revista Brasileira de Ciência do Solo, Viçosa, v.33, p.1571-1581, 2009.

APHA - AMERICAN PUBLIC HEALTH ASSOCIATION; AWWA - AMERICAN WATER WORKS ASSOCIATION; WEF - WATER ENVIRONMENT FEDERATION. Standard methods for the examination of water and wastewater. 21. ed. Washington: APHA/AWWA/ WEF, 2005. 1268p.

CARVALHO, J.A.;AQUINO, R.F.; PEREIRA, G.M.; RODRIGUES, R.C.; CAMPOS, T.B. Desempenho de bomba centrífuga operando com água residuária do processamento do café. Engenharia Agrícola, Jaboticabal, v.28, n.1, p.86-94, 2008.

LO MONACO, P.A.V.; MATOS, A.T.; SARMENTO, A.P.; LOPES JÚNIOR, A.V.; LIMA, J.T. Desempenho de filtros constituídos por fibras 
de coco no tratamento de águas residuárias de suinocultura. Engenharia na Agricultura, Viçosa, v.17, n.6, p.473-480, 2009b.

LO MONACO, P.A.V; MATOS, A.T.; MARTINEZ, H.E.P.; FERREIRA, P.A.; RAMOS, M.M. Características químicas do solo após a fertirrigação do cafeeiro com águas residuárias da lavagem e descascamento de seus frutos. Irriga, Botucatu, v.14, n.3, p.348-364, 2009a.

LO MONACO, P.A.; MATOS, A.T.; MARTINEZ, H.P.; FERREIRA, P.A.; RAMOS, M.M. Avaliação do estado nutricional do cafeeiro após a fertirrigação com águas residuárias da lavagem e descascamento de seus frutos. Engenharia na Agricultura, Viçosa, v.15, n.4, p.392-399, 2007.

LO MONACO, P.A.; MATOS, A.T.; JORDÃO, C.P.; CECON, P.C.; MARTINEZ, M.A. Influência da granulometria da serragem de madeira como material filtrante no tratamento de águas residuárias. Revista Brasileira de Engenharia Agrícola e Ambiental, Campina Grande, v.8, n.1, p.116-119, 2004.
MACHADO, M.C. Viabilidade de técnica de imersão para a Armazenagem temporária de frutos de café. Viçosa: UFV, 2005. 87p. Tese (Tese de Doutorado em Engenharia Agrícola), 2005.

MATOS, A.T. Tratamento de resíduos na póscolheita do café. In: BORÉM, F.M. (Ed.). Póscolheita do café. Lavras: Ed. UFLA, 2008. p.159-202.

MATOS, A.T.; LO MONACO, P.A. Tratamento e aproveitamento agrícola de resíduos sólidos e líquidos da lavagem e despolpa dos frutos do cafeeiro. Viçosa: Associação dos Engenheiros Agrícolas de Minas Gerais. Departamento de Engenharia Agrícola/UFV, 2003. 68p. (Boletim Técnico no. 7)

RIGUEIRA, R.J.A.; LACERDA FILHO, A.F.; MATOS, A.T.; DONZELES, S.M.L.; PALACIN, J.J.F. Alteração nas características físicas, químicas e bioquímicas da água no processo de lavagem, despolpa e desmucilagem de frutos do cafeeiro. Engenharia na Agricultura, Viçosa, v.18, n.2, p.131-139, 2010. 